\title{
Static stress transfer from the May 20, 2012, M 6.1 Emilia-Romagna (northern Italy) earthquake using a co-seismic slip distribution model
}

\author{
Athanassios Ganas ${ }^{1,{ }^{\star}}$, Zafeiria Roumelioti $^{2}$, Konstantinos Chousianitis $^{1}$ \\ ${ }^{1}$ National Observatory of Athens, Institute of Geodynamics, Athens, Greece \\ ${ }^{2}$ Aristotle University of Thessaloniki, Department of Civil Engineering, Laboratory of Soil Mechanics, Foundations and Geotechnical \\ Earthquake Engineering, Thessaloniki, Greece
}

\section{Article history}

Received July 28, 2012; accepted August 22, 2012.

Subject classification:

Seismology, Stress Transfer, Slip distribution, Italy.

\section{Introduction}

In May 2012, northern Italy (Figure 1) suffered two strong earthquakes that resulted in 26 deaths and widespread damage. The earthquakes struck in the Emilia-Romagna region to the north of the city of Bologna. The first strong event occurred on May 20, 2012, at 02:03:52.0 UTC, with an epicenter location at $44.889^{\circ} \mathrm{N}$ and $11.228^{\circ} \mathrm{E}$ determined by the Istituto Nazionale di Geofisica e Vulcanologia (INGV; National Institute of Geophysics and Volcanology), a focal depth of $6.3 \mathrm{~km}$, and a moment magnitude of M 6.1 (Global Centroid Moment Tensor Catalog, CMT). The second event occurred on May 29, 2012, at 07:00:03 UTC with an epicenter location of $44.851^{\circ} \mathrm{N}$ and $11.086^{\circ} \mathrm{E}$ (determined by INGV), a depth of $10.2 \mathrm{~km}$, and a magnitude of $\mathrm{M}_{\mathrm{W}}$ 5.9. The distance between the epicenters was $11.9 \mathrm{~km}$, which indicated some form of interaction between the two events, given also the short time interval ( 9 days) and the similarity in the focal mechanisms (thrust-type of faulting). The Emilia-Romagna area is underlain by a series of active thrust faults and related folds, which strike WNW-ESE, parallel to the mountain front, and which dip shallowly towards the south-southwest. This region comprises a foreland basin formed by the downflexing of the crust because of the loading of the northern Apennine thrust sheets, across which there is about one millimeter per year of active shortening at present [e.g., Devoti et al. 2011, Bennett et al. 2012].

In the present study, we provide evidence of earthquake triggering through stress transfer. First, we investigate a heterogeneous slip model for the May 20, 2012, earthquake, and subsequently we apply the slip model in static stress change calculations for both optimal planes for failure and the specific fault planes of the May 29, 2012, earthquake in northern Italy.

\section{Methods}

2.1. Slip distribution of the May 20, 2012, M 6.1 EmiliaRomagna earthquake

The distribution of slip on the ruptured plane of the M 6.1 Emilia-Romagna earthquake was investigated using empirical Green's functions (eGFs) [Hartzell 1978] and a least-squares inversion scheme of source time functions (STFs) computed from regional broadband seismological data [Mori and Hartzell 1990, Dreger 1994].

To briefly describe the eGF method, we consider the mathematical representation of the far-field wave displacement of a point source, $\mathrm{U}(\omega)$ recorded at distance $\mathrm{r}$ and azimuth $\phi$ :

$$
U(\omega)=\dot{M}(\omega) \cdot G(\omega, r, \phi) \cdot R \cdot I(\omega)
$$

where $\omega$ is the angular frequency, $\dot{M}$ is the moment rate function of the event, $G$ is the Green's function response of the medium along the wave path, which includes the effects of attenuation and geometrical spreading, $R$ is the radiation pattern factor, and $I$ is the response of the recording instrument. By deconvolving a smaller event, i.e., an event with a STF that can be considered negligible relative to the STF of the larger event, all three factors of $G, R$ and $I$ are empirically removed. STFs computed through the deconvolution procedure are then inverted to reveal the characteristics of the source process. All STFs are normalized to unit area, i.e., only the shapes and not the absolute amplitudes of the STFs are inverted. The source parameterization in the inversion procedure includes a rectangular fault surface, which is divided into a certain number of subfaults. A radially expanding rupture front with constant rupture velocity is then considered, with the slip confined to one of the nodal planes, as determined by the focal mechanism of the event exam- 


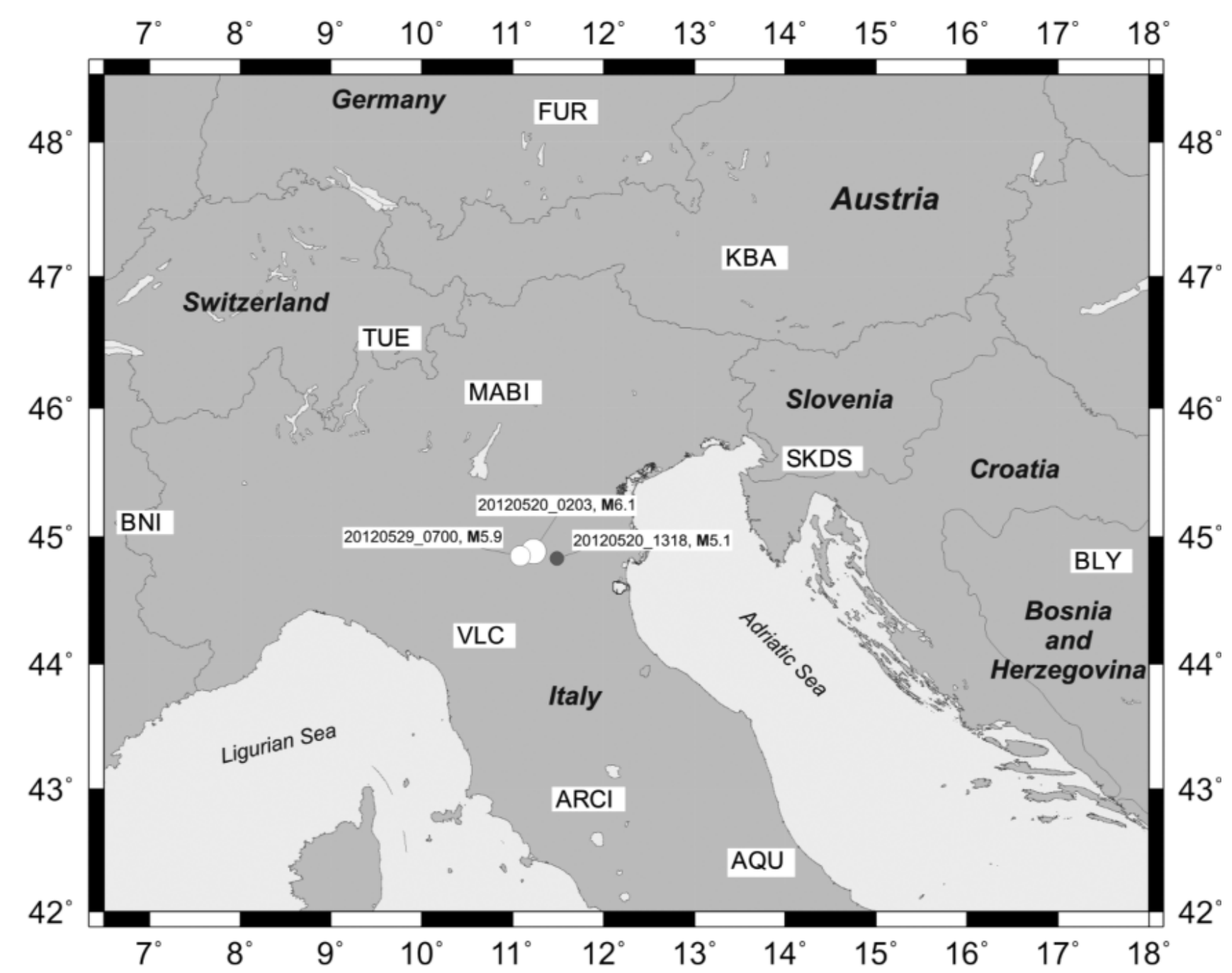

Figure 1. Regional map showing the locations of the stations used relative to the epicenters of the May 20, 2012, M 6.1 earthquake and the May 29, 2012, M 5.9 event. The May 20, 2012, aftershock was used as an empirical Green's function.

\begin{tabular}{lccccccccccc}
\hline Event & $\begin{array}{c}\text { Date } \\
(\mathrm{dd} / \mathrm{mm} / \mathrm{yy})\end{array}$ & $\begin{array}{c}\text { Time } \\
\text { (hh:mm:ss })\end{array}$ & $\begin{array}{c}\text { Latitude Longitude } \\
\left({ }^{\circ} \mathrm{N}\right)\end{array}$ & $\begin{array}{c}\text { Depth } \\
\left({ }^{\circ} \mathrm{E}\right)\end{array}$ & $\begin{array}{c}\text { M } \\
(\mathrm{km})\end{array}$ & $\begin{array}{c}\text { Mo } \\
\left(\times 10^{18} \mathrm{Nt} \times \mathrm{m}\right)\end{array}$ & $\begin{array}{c}\text { Plane 1 } \\
\text { Strike/Dip } / \mathrm{Rake}\left({ }^{\circ}\right)\end{array}$ & $\begin{array}{c}\text { Plane 2 } \\
\left({ }^{\circ}\right)\end{array}$ & $\begin{array}{c}\text { P-axis } \\
(\mathrm{Pl} / \mathrm{Az})\end{array}$ & $\begin{array}{c}\text { T-axis } \\
(\mathrm{Pl} / \mathrm{Az})\end{array}$ \\
\hline Main I & $20 / 05 / 12$ & $02: 03: 52$ & 44.889 & 11.228 & 6.3 & 6.1 & 1.66 & $96 / 35 / 68$ & $302 / 58 / 105$ & $12 / 21$ & $73 / 249$ \\
eGF & $20 / 05 / 12$ & $13: 18: 02$ & 44.831 & 11.490 & 4.7 & 5.1 & 0.066 & $110 / 38 / 82$ & $300 / 51 / 96$ & $6 / 26$ & $82 / 246$ \\
Main II & $29 / 5 / 2012$ & $07: 00: 03$ & 44.851 & 11.086 & 10 & 5.9 & 0.767 & $100 / 30 / 81$ & $290 / 60 / 95$ & $15 / 17$ & $72 / 214$ \\
\hline
\end{tabular}

Table 1. Source parameters for the two strongest events of the May 2012 Emilia-Romagna sequence and the strong aftershock, which was used as empirical Green's function. Locations are from http:/ / iside.rm.ingvit and moment tensor related parameters are from the global Centroid Moment Tensor solutions catalog (http:/ /www.globalcmt.org/). eGF, empirical Green's function.

ined. The fit to each observed STF is determined by summing the synthetics from different parts along the fault, which are positioned at equal intervals. These synthetics are appropriately delayed by taking into account the time needed for the wave to propagate from the hypocenter to the recording station, and the time delay due to the propagation of the rupture front. Distances to the different subfaults are estimated using a half-space ray trajectory approximation. It is also assumed that the contribution from each subfault has the form of a boxcar function. The length of the boxcar represents the slip duration of each subfault, and it is fixed in each inversion. The optimal values for the rupture velocity and the dislocation rise time, which are also fixed in each inversion, are found by performing a series of inversions testing the parameter space.

The subfault STFs $(B)$ are related to the observed STFs $(D)$ through a system of equations of the form:

$$
D_{i}(t)=\operatorname{STF}_{i}(t)=\sum_{j}^{m} B_{j}\left(t-\tau_{i j}\right) w_{j}
$$

where $\tau$ is the time delay due to wave and rupture propagation, $i$ is a station index, $j$ is a subfault index, and $w$ is a weight proportional to the fault slip. Two constraints are imposed on the inversion procedure. The first is a positivity con- 


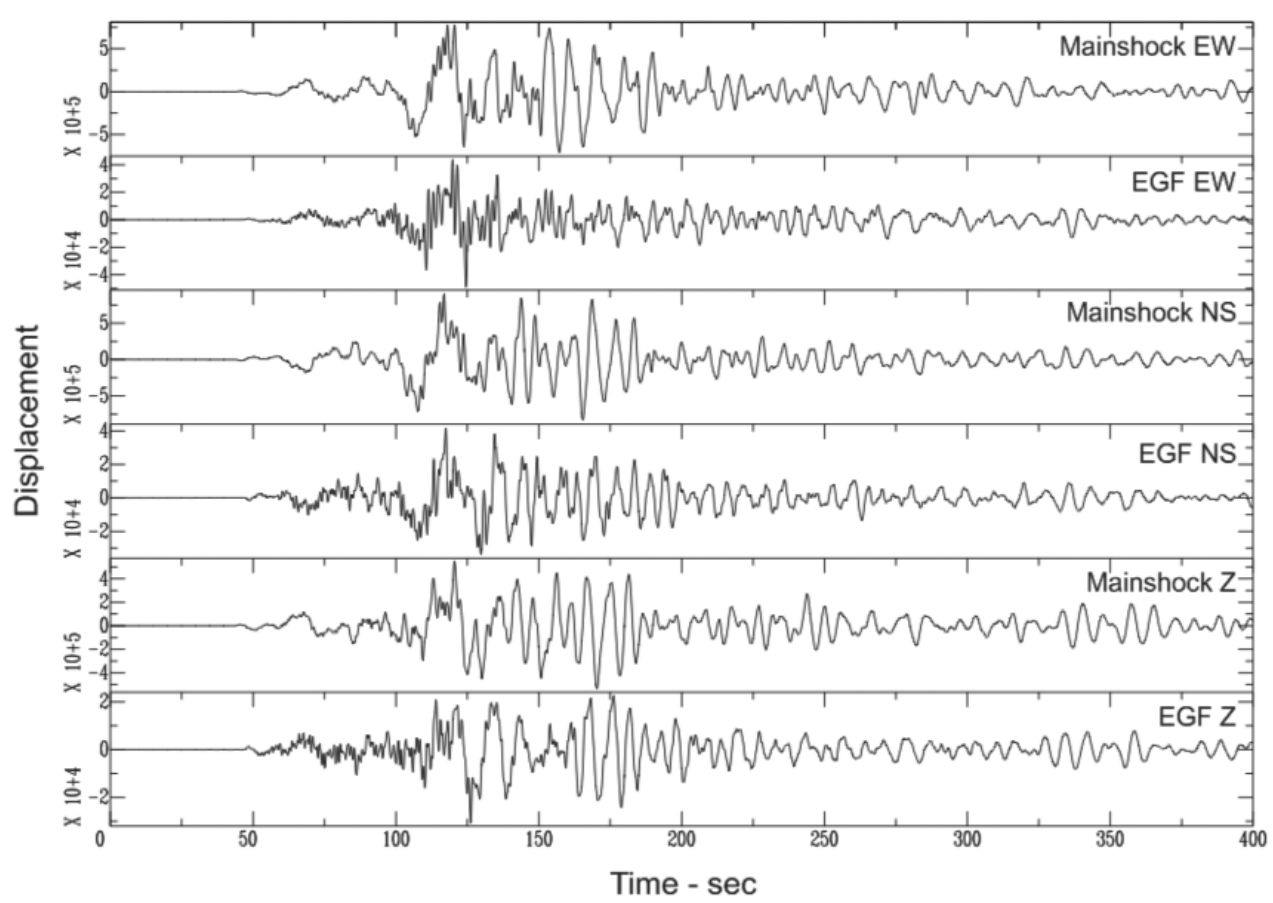

Figure 2. Comparison of the eGF displacement waveforms with the corresponding studied mainshock waveforms for the three components (top, EW; middle, NS; bottom, Z) of station AQU. All of the waveforms were bandpass filtered in the frequency range $0.01 \mathrm{~Hz}$ to $1 \mathrm{~Hz}$.
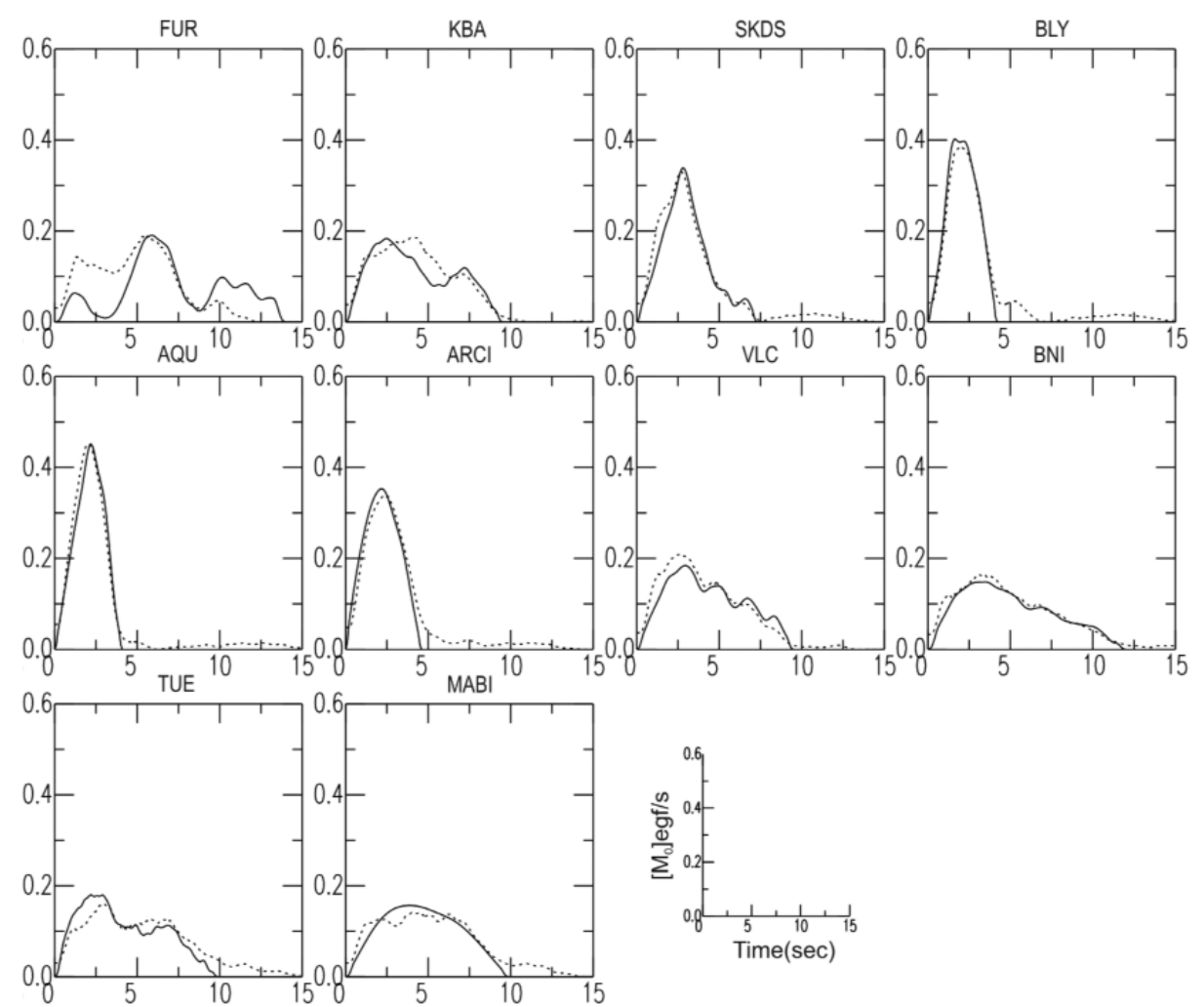

Figure 3. Comparison of synthetic (dashed lines) and computed STFs at the ten stations shown in Figure 1. Synthetic STFs were derived using the slip distribution model of Figure 4.

straint, which allows only those subfaults with positive slip to contribute to the solution, and the second is a spatial derivative minimization constraint to smooth the resulting slip model. Taking into account the two constraints, Equation 2 can be rewritten in a matrix form as:

$$
\left[\frac{\mathbf{B}}{\lambda \mathbf{S}}\right] \cdot w=\left[\frac{\mathbf{D}}{0}\right]
$$

where $\boldsymbol{S}$ is the matrix of first spatial derivatives, and $\lambda$ is a constant controlling the weight of the smoothing equation. 


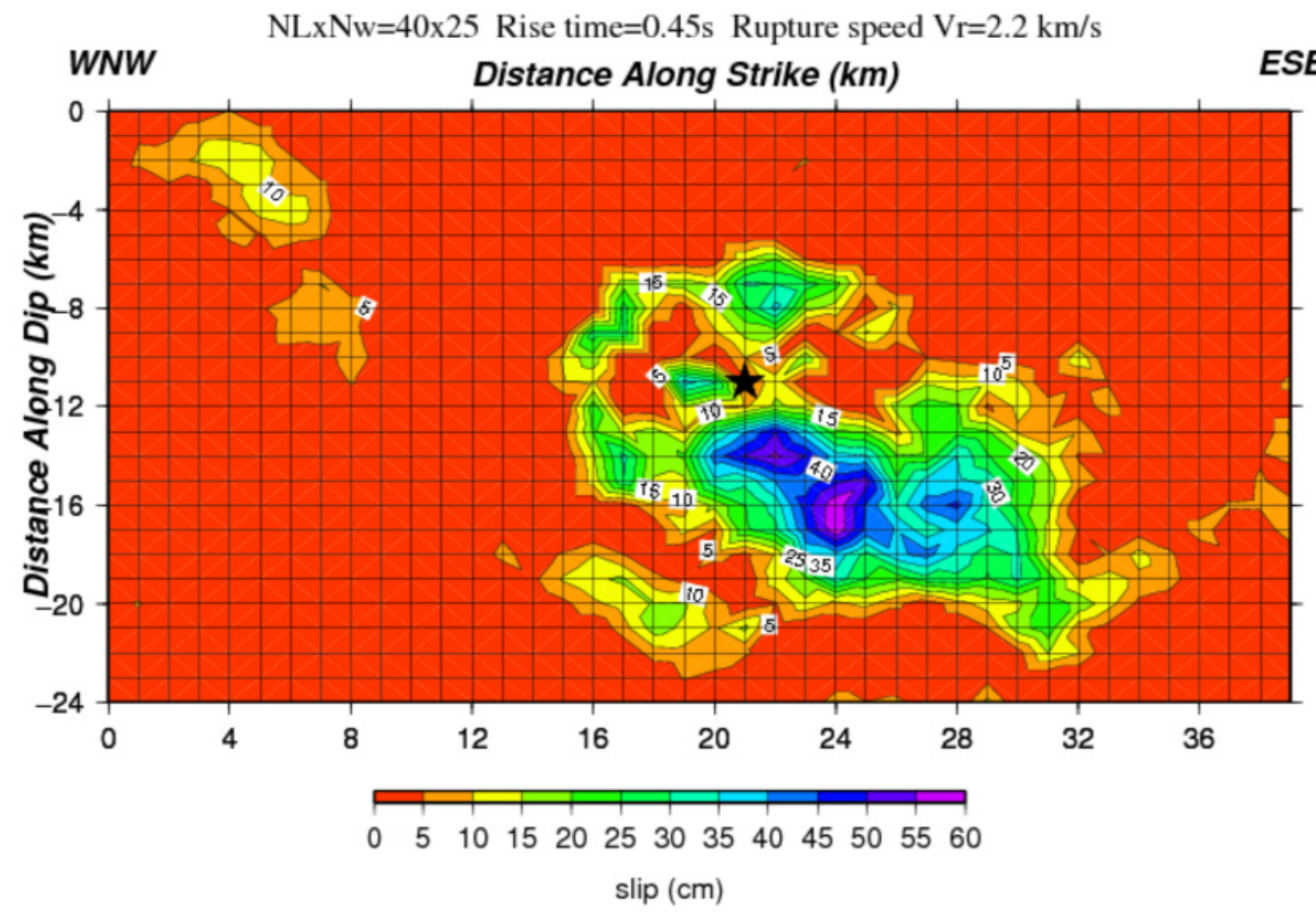

Figure 4. Slip distribution model for the 2012, M 6.1 Emilia mainshock. The contours are for $5 \mathrm{~cm}$ intervals of slip, beginning at $5 \mathrm{~cm}$. Black star, adopted hypocentral location.

The slip weight vector is obtained by standard least squares. The timing of slip on each subfault is controlled by the radially expanding rupture front, and each part is allowed to rupture only once. Since the inversion yields slip weights and not absolute slip amplitudes, to derive the absolute slip at each subfault, $u_{j}$, an independent estimate of the seismic moment, $M_{0}$, is required.

\subsubsection{Data}

The data used in this study were obtained from the Orfeus web page (http:/ / www.orfeus-eu.org/) and were provided by MEDNET and the Italian, German, Austrian and Slovenian National Seismic Networks. The distribution of the stations used in the inversion, relative to the Emilia mainshock, is shown in Figure 1. The selection of the stations was based on availability, as well as azimuth criteria, i.e., obtaining the best azimuthal coverage of the epicentral area without overweighting the azimuths where the data availability was greater.

\subsubsection{Application and results}

In the present study, an aftershock of M 5.1 that occurred on May 20, 2012, at 13:18:02 UTM was identified as the most appropriate to be used in the study of the May 20, M 6.1 mainshock. The basic source parameters of these two events are shown in Table 1 . The original velocity broadband waveforms of both the studied mainshock and the
eGFs were integrated into the displacement and band-pass filtered between $0.01 \mathrm{~Hz}$ and $1 \mathrm{~Hz}$, using a causal fourthorder Butterworth filter. The eGF waveforms were then deconvolved from the mainshock waveforms in the frequency domain, using a $1 \%$ water level (i.e., small values in the denominator were replaced by 0.01 times the maximum value of the denominator [Clayton and Wiggins 1976] to stabilize the process. An indicative example of the comparison of the eGF waveforms with the mainshock waveforms is presented in Figure 2.

The computed STFs were normalized to unit area, and are shown in Figure 3 (continuous lines). The STF shapes present significant variations with smaller duration and larger amplitude to the ESE direction (e.g., BLY, AQU), and vice versa. This phenomenon is indicative of the emergence of rupture directivity effects. Thus, based on the STF shapes, it is concluded that the rupture on the fault plane of the May 20, 2012, M 6.1 event propagated from the hypocenter to the ESE. In the inversion of the STF shapes, we assumed a planar fault model with dimensions $40 \mathrm{~km} \times 25 \mathrm{~km}$, discretized into $1 \mathrm{~km}^{2}$ subfaults. The dimensions of the fault model were chosen to be larger than those expected for an earthquake of M 6.1 [e.g. Wells and Coppersmith 1994], to allow for possible unilateral propagation of the rupture in any direction. The optimum values for the rupture velocity and the rise time were determined through iterative inversions in a grid of the parameter space $\left(V_{r}=2.2 \mathrm{~km} / \mathrm{s}, \tau=0.45 \mathrm{~s}\right)$. These best-fit 

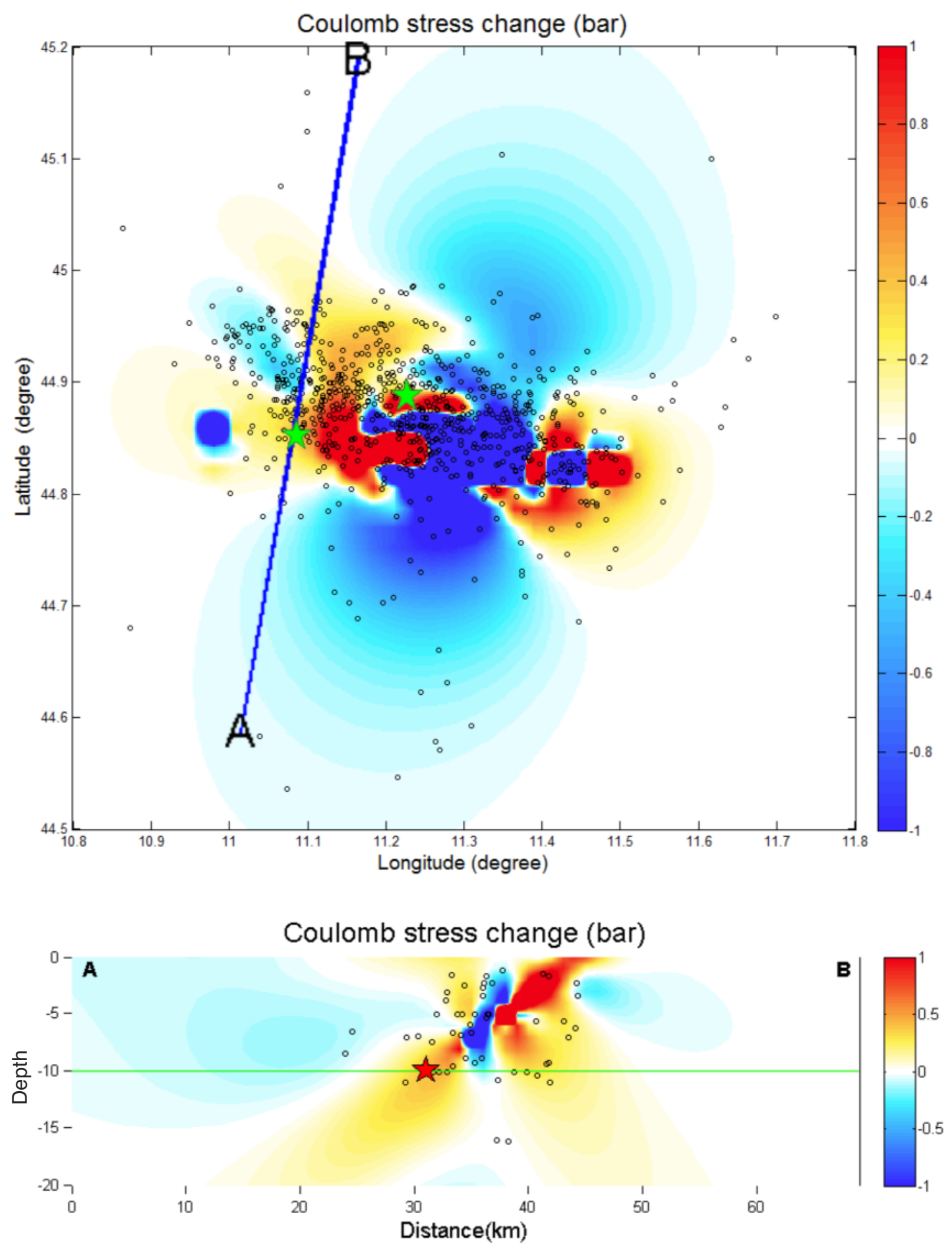

Figure 5. Coulomb stress changes at 10-km depth associated with the May 20, 2012, 02:03 $\mathrm{UTC}_{\mathrm{W}} 6.1$ earthquake. The palette of stress values is linear in the range -1 to +1 bar. Green stars, the two mainshock epicenters. Blue areas, unloading; red areas, loading. Color scale in bar $(1 \mathrm{bar}=100 \mathrm{KPa})$. Open circles are consequent events after the May 20, 2012, mainshock. The source slip model is that of Figure 4. (a) Map and (b) vertical cross-section crossing the hypocenter of the May 29, 2012, event heading N10 ${ }^{\circ} \mathrm{E}$ (normal to fault strike of the May 29, 2012, event). Green line, horizontal section of $\Delta \mathrm{CFF}$ distribution shown in Figure 5a.

values were used to obtain the final slip distribution model, for which we obtained a variance reduction of $94.5 \%$. In Figure 3, we present the comparison of the final synthetic STFs (dashed lines) with the computed ones (continuous lines).

Figure 4 shows a map of the resulting slip. The slip, averaged across the ruptured fault surface, is ca. $13.8 \mathrm{~cm}$, while its peak value is as high as $59 \mathrm{~cm}$. Most of the slip appears below and to the ESE of the hypocenter location (Figure 4, star symbol), thus below ca. $6 \mathrm{~km}$. The dimensions of the ruptured area (along strike $\times$ along dip) are approximately $17 \mathrm{~km} \times 16 \mathrm{~km}$, and the slip does not reach the ground surface (upper edge of the fault model is at $0 \mathrm{~km}$ ). However, it must be noted that the latter result is subject to the error in the hypocentral depth; i.e., if the hypocentral depth is 

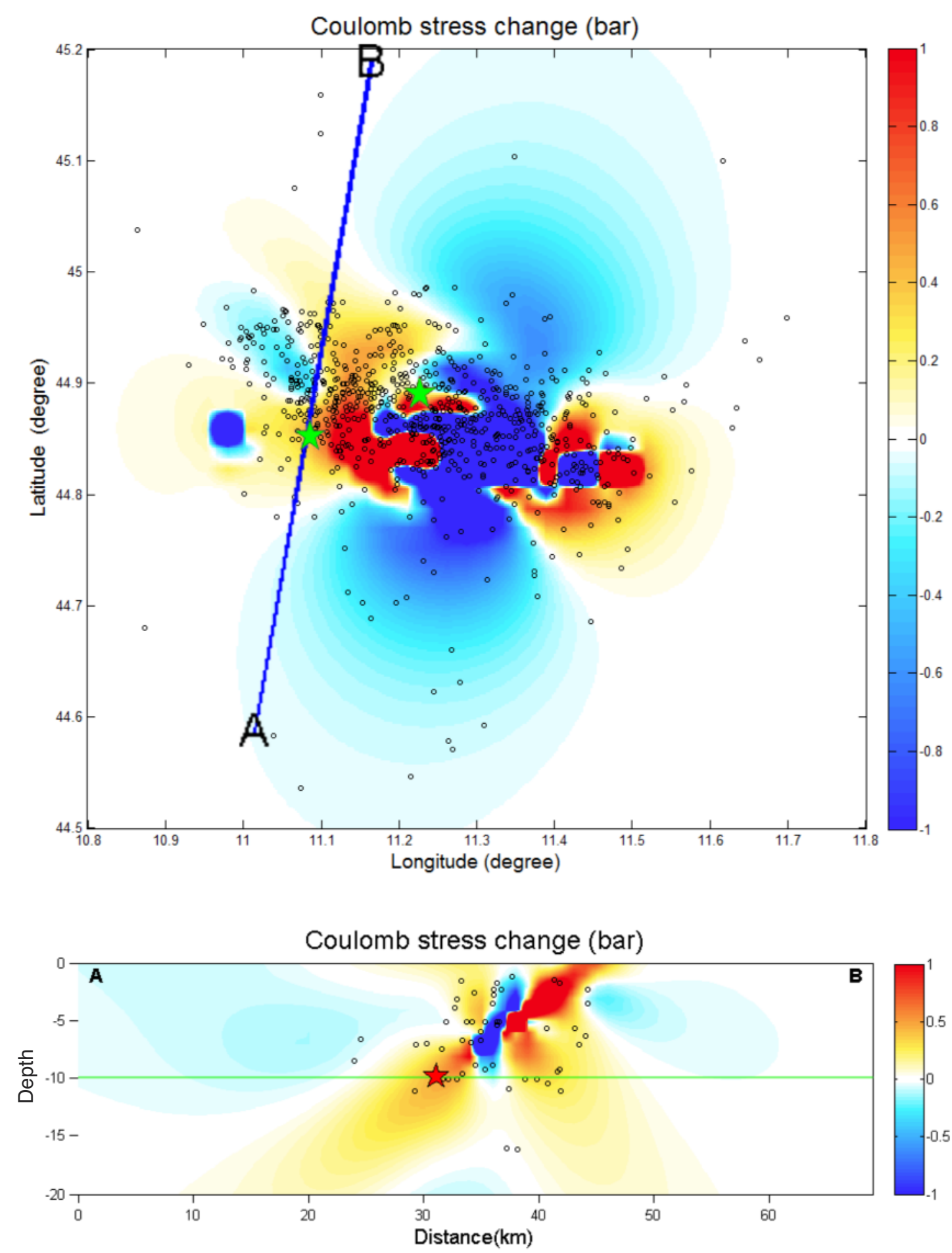

Figure 6. Coulomb stress distribution as in Figure 5, but for low-angle, reverse receiver faults striking N100 ${ }^{\circ} \mathrm{E}$ with friction of 0.4 . Open circles, consequent events after May 20, 2012, mainshock. (a) Map and (b) vertical cross-section. Green line, horizontal section of $\triangle \mathrm{CFF}$ distribution shown in Figure 6a.

shallower, the entire model will be shifted to shallower depth. The small slip concentrations close to the upper left corner of the fault model disappear when data from stations TUE and MABI are excluded from the inversion. Comparison of synthetic STFs derived with and without these small slip concentrations revealed that these small patches are needed to slightly improve the STF fit at stations TUE and MABI in the time window of $2.5 \mathrm{~s}$ to $5 \mathrm{~s}$. As this result is azimuth dependent and relative values are too small to be con- sidered well resolved, we consider it as an artefact of our analysis. Different sets of data and a near-fault of higher frequency are needed to clarify the existence of such scale irregularities in the slip distribution model.

\subsection{Stress transfer modeling}

Earthquakes on fault planes can trigger subsequent earthquakes at short distances from the hypocenter by transferring static stresses [e.g., Harris et al. 1995, Gomberg 
et al. 2001, Freed 2005, Ganas et al. 2008, 2010, Parsons et al. 2008]. We model stress transfer assuming that failure of the crust occurs by shear, so that the mechanics of the process can be approximated by the Okada [1992] expressions for the displacement and strain fields due to a finite rectangular source in an elastic, homogeneous and isotropic half-space. We use the Coulomb 3.3 software [Lin and Stein 2004, Toda et al. 2005] to compute the static Coulomb stress change by assuming a Young modulus of $8 \times 10^{5}$ bar, Poisson's ratio 0.25 , and effective coefficient of friction $\mu^{\prime}=0.4$, which is closer to friction values for major faults [Harris and Simpson 1998].

We calculated the change in the Coulomb failure function (CFF, or Coulomb stress), on target failure planes [Reasenberg and Simpson 1992],

$$
\Delta \mathrm{CFF}=\Delta \tau+\mu^{\prime} \Delta \sigma_{\eta}
$$

where $\Delta \tau$ is the co-seismic change in shear stress on the receiver fault, and in the direction of fault slip, $\Delta \sigma_{\eta}$ is the change in the normal stress (with tension positive), and $\mu^{\prime}$ is the effective coefficient of friction. $\triangle \mathrm{CFF}$ is the Coulomb stress change between the initial (ambient) stress and the final stress. Moreover, we checked the robustness of our results by using $\mu^{\prime}$ values from 0.1 to 0.8 . In all cases, the spatial distribution of $\triangle \mathrm{CFF}$ values does not change significantly compared to the results obtained for $\mu^{\prime}=0.4$. We interpret a positive value of $\triangle \mathrm{CFF}$ to indicate that a fault plane that occurred within this stress lobe has been brought closer to failure; when $\triangle \mathrm{CFF}$ is negative, the fault is brought further from failure (i.e., relaxed).

2.2.1. Triggering of the May 29, 2012, earthquake: calculation of DCFF on optimal planes

We computed the $\triangle$ CFF caused by the May 20, 2012, event on optimally oriented planes to regional compression (assuming a deviatoric stress magnitude of 200 bar; Figure 5). For the compression azimuth, we adopted the orientation of the P-axis of the focal plane solution of the May 20, 2012, event $\left(\mathrm{N} 21^{\circ} \mathrm{E}\right.$; Table 1$)$. The calculation was carried out for seismogenic depths (in the $5-11 \mathrm{~km}$ range), including the depth of the May 29, 2012, event hypocenter $(10 \mathrm{~km})$. The target planes are similar in orientation to the May 20, 2012, fault plane; i.e., they strike E-W and dip either to the $\mathrm{N}$ or the $\mathrm{S}$. We calculate the stress tensor on horizontal observation planes. $\triangle \mathrm{CFF}$ was sampled on a 40 $\mathrm{km} \times 40 \mathrm{~km}$ grid, with $1 \mathrm{~km}$ grid spacing. The calculations consider an inclined rectangular dislocation that ruptured on May 20, 2012, according to our slip model (Figure 4). Figure 5 shows the distribution of the Coulomb stress at a depth of $10 \mathrm{~km}$ (depth of May 29, 2012, hypocentre; INGV solution) for optimal planes to regional compression ( $\mathrm{N}$ $\left.21^{\circ} \mathrm{E}\right)$. The static stress transfer in the area of the May 29,
2012, earthquake amounts to 0.61 bar to 0.74 bar.

2.2.2. Triggering of the May 29, 2012, earthquake: calculation of DCFF, on May 29, 2012, target (receiver) planes

We also evaluated the capability of the source fault (i.e., the first $\mathrm{M}_{\mathrm{W}} 6.1$ event on May 20, 2012, at 02:03 UTC) to trigger earthquakes along faults of geometrical characteristics and kinematics identical to those suggested by the May 29, 2012, M 5.9, focal mechanism. The target (receiver) planes are modeled as left-lateral reverse faults, with slip models identical to those of the May 29, 2012, 07:00 UTC event (strike/ dip / rake: $100^{\circ} / 30^{\circ} / 81^{\circ}$ ). We evaluated the amount of static Coulomb stress that was transferred to the region of occurrence of the May 29, 2012, event (Figure 6), by sampling CFF on a horizontal section at $10 \mathrm{~km}$ depth on a $40 \mathrm{~km} \times 40 \mathrm{~km}$ grid surrounding the source event epicenter, with a $1 \mathrm{~km}$ grid spacing. Figure 6 shows the distribution of Coulomb stress where the static stress transfer in the area of the May 29, 2012, earthquake amounts to 0.61 bar to 0.74 bar.

\section{Discussion and conclusions}

The slip distribution of the May 20, 2012, M 6.1 Emilia-Romagna earthquake was investigated through an inversion methodology of the STF shapes, to incorporate it into realistic Coulomb stress transfer computations. The study of the May 20, 2012, earthquake source revealed that the area that ruptured was approximately $17 \mathrm{~km} \times 16 \mathrm{~km}$ (along strike $\times$ along dip), with a mean slip of ca. $14 \mathrm{~cm}$ and a peak of $59 \mathrm{~cm}$. The slip appeared mostly to the E-SE of the adopted hypocenter location, and did not reach the ground surface.

Both triggering models predict that the hypocenter of the second mainshock $\left(\mathrm{M}_{\mathrm{W}}\right.$ 5.9) is in the crustal region where static stress was transferred. The results considering target planes similar to the May 29, 2012, nodal plane (Figure 6) resemble those on optimal planes (Figure 5). This result is indicative that the May 29, 2012, event might have been triggered by the preceding May 20, 2012, M 6.1 earthquake due to static stressing by fault slip (Figure 4). The loading stress levels are of the order of 0.61 bars to 0.74 bars (Figures 5, 6).

Most first-event (i.e., post May 20, 2012) aftershocks occur inside the loaded areas of the crust (total 770 events; Figures 5, 6). A few aftershocks occur inside these relaxed areas and within a distance of $2 \mathrm{~km}$ from the vertical crosssection that passes through the hypocenter of the second strongest event (Figures 5b, 6b). Their occurrence might be attributed to misfit of the coseismic slip model (Figure 4), dynamic stress triggering [Gomberg et al. 2001], or the location uncertainty of the catalog [Catalli and Chan 2012]. We infer that our stress change calculations have been adequately validated by the observed distribution of aftershocks. 
Acknowledgements. We thank Marco Anzidei and Christodoulos Kyriakopoulos for preliminary reports and information on the May 2012 Italian earthquakes. We thank the reviewers C. Chan and R. Console for comments and suggestions. This work was financed in part by the General Secretariat of Research and Technology (Ministry of Development) of Greece. Figure 1-3 were made using the Generic Mapping Tools software [Wessel and Smith 1991]. We acknowledge the use of the INGV earthquake catalog.

\section{References}

Bennett, R.A., E. Serpelloni, S. Hreinsdóttir, M.T. Brandon, G. Buble, T. Basic, G. Casale, A. Cavaliere, M. Anzidei, M. Marjonovic, G. Minelli, G. Molli and A. Montanari (2012). Syn-convergent extension observed using the RETREAT GPS network, northern Apennines, Italy, J. Geophys. Res., 117, B04408; doi:10.1029/2011JB008744.

Catalli, F., and C.H. Chan (2012). New insights into the application of the Coulomb model in real-time, Geol. J. Int., 188; doi:10.1111/j.1365-246X.2011.05276.x.

Clayton, R.W., and R.A. Wiggins (1976). Source shape estimation and deconvolution of teleseismic body waves, Geophys. J. Roy. Astron. Soc., 47, 151-177.

Devoti, R., A. Esposito, G. Pietrantonio, A.R. Pisani and F. Riguzzi (2011). Evidence of large scale deformation patterns from GPS data in the Italian subduction boundary, Earth Planet. Sci. Lett., 311, 230-241.

Dreger, D. (1994). Empirical Green's function study of the January 17, 1994, Northridge, California earthquake, Geophys. Res. Lett., 21, 2633-2636.

Freed, A.M. (2005). Earthquake triggering by static, dynamic, and postseismic stress transfer, Ann. Rev. Earth Planet. Sci., 33, 335.

Ganas, A., A. Gosar and G. Drakatos (2008). Static stress changes due to the 1998 and 2004 Krn Mountain (Slovenia) earthquakes and implications for future seismicity, Nat. Haz. Earth Syst. Sci., 8, 59-66.

Ganas, A., B. Grecu, E. Batsi and M. Radulian (2010). Vrancea slab earthquakes triggered by static stress transfer, Nat. Hazards Earth Syst. Sci., 10, 2565-2577.

Gomberg, J., P.A. Reasenberg, P. Bodin and R.A. Harris (2001). Earthquake triggering by seismic waves following the Landers and Hector mine earthquakes, Nature, 411, 462-466.

Harris, R.A., R.W. Simpson and P.A. Reasenberg (1995). Influence of static stress changes on earthquake locations in southern California, Nature, 375, 221-224.

Harris, R.A., and R.W. Simpson (1998). Suppression of large earthquakes by stress shadows: a comparison of Coulomb and rate and state failure, J. Geophys. Res., 103, 439-451.

Hartzell, S.H. (1978). Earthquake aftershocks as Green's functions, Geophys. Res. Lett., 5, 1-4.

Lin, J., and R. Stein (2004). Stress triggering in thrust and subduction earthquakes, and stress interaction between the southern San Andreas and nearby thrust and strike- slip faults, J. Geophys. Res., 109, B02303; doi:10.1029/ 2003JB002607.

Mori, J., and S. Hartzell (1990). Source inversion of the 1988 Upland earthquake: determination of a fault plane for a small event, B. Seismol. Soc. Am., 80, 278-295.

Okada, Y. (1992). Internal deformation due to shear and tensile faults in a half-space, B. Seismol. Soc. Am., 82, 1018-1040.

Parsons, T., C. Ji and E. Kirby (2008). Stress changes from the 2008 Wenchuan earthquake and increased hazard in the Sichuan Basin, Nature, 454, 509-510; doi: 10.1038 / nature 07177

Reasenberg, P.A., and R.W. Simpson (1992). Response of regional seismicity to the static stress change produced by Loma Prieta earthquake, Science, 255, 1687-1690.

Toda, S., R.S. Stein, K. Richards-Dinger and S. Bozkurt (2005). Forecasting the evolution of seismicity in southern California: animations built on earthquake stress transfer, J. Geophys. Res., B05S16; doi:10.1029/2004JB 003415.

Wells, D.L., and K.J. Coppersmith (1994). New empirical relationships among magnitude, rupture length, rupture width, rupture area, and surface displacement, B. Seismol. Soc. Am., 84, 974-1002.

Wessel, P., and W.H.F. Smith (1991). Free GMT software helps map and display data, EOS Trans. AGU, 72, 441-456.

${ }^{\star}$ Corresponding author: Athanassios Ganas, National Observatory of Athens, Institute of Geodynamics, Athens, Greece; email: aganas@noa.gr.

C 2012 by the Istituto Nazionale di Geofisica e Vulcanologia. All rights reserved. 